\title{
Treatment of Delusions in Dementia with Lewy Bodies - Response to Pharmacotherapy
}

\author{
Corinne Fischer ${ }^{a, b}$ Radenka Bozanovic ${ }^{c}$ Jana H. Atkins ${ }^{a}$ Sean B. Rourke ${ }^{a, b, d}$ \\ aSt. Michael's Hospital, b Department of Psychiatry, University of Toronto, 'Mount Sinai Hospital and \\ dOntario HIV Treatment Network, Toronto, Ont., Canada
}

\section{Key Words}

Delusions - Dementia with Lewy bodies - Psychosis •

Antipsychotics $\cdot$ Neuroleptics

\begin{abstract}
Background: Delusions are clinically important symptoms in dementia with Lewy bodies (DLB). The purpose of this review is to examine the level of evidence for treatment of delusions in DLB. Methods: To achieve this objective Medline was searched. Studies were included in the review if they were prospective, separated delusions from hallucinations and were tested in patients with DLB. Results: The review yielded a total of six studies. Although all studies showed effectiveness, only one study using rivastigmine had an adequate patient sample size and used a randomized controlled design. Conclusion: Further studies are required before a definitive conclusion can be reached about effective treatments.

Copyright $\odot 2007$ S. Karger AG, Base
\end{abstract}

\section{Introduction}

Dementia with Lewy bodies (DLB) has been recognized in recent years as a distinct and clinically prevalent subtype of dementia. In fact, recent estimates suggest and pathologic diagnoses corroborate that DLB may be second in prevalence to Alzheimer's disease (AD) [1]. Al- though the neuropathological criteria for DLB have been better established, the clinical criteria for this diagnosis have been harder to establish. Much of this has to do with overlap with existing conditions, such as Parkinson's dementia and AD. Recent attempts to validate the diagnosis of DLB have shown that clinical criteria are reasonably specific but lack sensitivity $[1,2]$. In spite of the confusion, it is generally agreed that patients with DLB must meet certain clinical criteria as outlined in the third report of the DLB consortium [3]. These include a diagnosis of dementia and 2 of 3 core features (fluctuating cognition, prominent visual hallucinations, parkinsonism). In addition, a number of supportive and suggestive features have been added, which include the presence of neuroleptic sensitivity and rapid eye movement sleep disorder. To qualify for a diagnosis of probable DLB, patients must have more than 1 core feature, or 1 core feature present with 1 or more suggestive features. Patients with possible DLB must have more than 1 suggestive feature present. The refinement in diagnostic criteria is an attempt to better capture patients with DLB and to better differentiate patients with DLB from patients with Parkinson's disease (PD) or AD.

It is generally agreed that patients with DLB, when compared for example to patients with other subtypes of dementia such as $\mathrm{AD}$, have more prominent psychiatric features $[4,5]$. Furthermore, psychiatric symptoms tend to emerge earlier in the course of DLB. Studies examining the psychopathology of DLB have generally shown a wide

\section{KARGER}

Fax +41613061234 E-Mail karger@karger.ch www.karger.com
(C) 2007 S. Karger AG, Basel

$1420-8008 / 07 / 0235-0307 \$ 23.50 / 0$

Accessible online at:

www.karger.com/dem
Dr. Corinne Fischer

rm17044, 17 Cardinal Carter Wing

St. Michael's Hospital, No. 30 Bond Street

Toronto, Ont. M5B 1W8 (Canada)

Tel. +1 416864 5320, Fax +1 416864 5480, E-Mail fischerc@smh.toronto.on.ca 
spectrum of psychiatric features, including depression and psychosis (delusions and hallucinations) $[4,5]$. Visual hallucinations tend to be most prevalent and are considered a core diagnostic criterion, whereas systematized delusions tend to be less prevalent and constitute a supportive feature [3]. One factor that has complicated the pharmacological treatment of these symptoms is the issue of neuroleptic sensitivity. Early studies suggested that patients with DLB who were given neuroleptics could be at risk for severe life-threatening reactions [6]. More recent studies have disputed this [7], instead suggesting that such medications may be used with caution, specifically those associated with minimal extrapyramidal effects. Aarsland et al. [8] recently attempted to clarify the risk associated with use of neuroleptics in patients with DLB and related conditions such as Parkinson's dementia and PD. They compared patients with DLB, Parkinson's dementia and PD to patients with $\mathrm{AD}$ in terms of the frequency of neuroleptic sensitivity over an 8-year period, concluding that severe sensitivity to neuroleptics only occurs in DLB and related conditions at rates ranging from 27 to $53 \%$.

Given the potential risks associated with use of neuroleptic medications, there are few early studies looking at utilization of these medications in patients with DLB. Cognitive enhancers, on the other hand, have not been shown to have any adverse effects specific to this population and therefore have been used more liberally. While there have been several studies examining the impact of various pharmacologic treatments on behaviour in patients with DLB, no studies to date have focused exclusively on subtypes of behavioural symptoms such as delusions. This may be important, as it is well understood that neuropsychiatric symptoms in disorders such as DLB can be quite diverse and have different neuropathological mechanisms. In fact, recent work by Ballard et al. [9] suggests that delusions may be related to upregulation of muscarinic receptors, whereas visual hallucinations may be related to disturbances in cholinergic transmission. These findings provide justification for why treatment of psychiatric symptoms such as delusions in DLB should be looked at in isolation. The purpose of this paper is to examine the level of evidence for treatment of delusions in patients with DLB.

\section{Methods}

A comprehensive Medline search was conducted using the key words dementia with Lewy bodies, psychosis, delusions and treatment. To be part of the review, studies had to include exclusively patients with DLB, use a specific measure of delusions [such as the Neuropsychiatric Inventory (NPI) delusion subscale], be prospective, involve a pharmacologic approach to treatment and use a monotherapy. Studies using multiple therapies, including patients with mixed diagnoses with a retrospective design, were excluded.

\section{Results}

A comprehensive Medline search yielded a total of 6 citations which met the specified inclusion and exclusion criteria (table 1). Four of these studies involved use of cholinesterase inhibitors [10-13], while 2 used neuroleptics $[14,15]$. All of the studies showed benefit, although the vast majority had small sample sizes.

Among the cholinesterase inhibitors, all 3 were tried and showed benefit. Rivastigmine $[12,13]$, however, had the largest number of positive studies (2) and was the only study to use a relatively large sample size and a randomized placebo-controlled design [12]. The large rivastigmine study [12] which compared rivastigmine to placebo in a number of domains showed a significant difference compared with placebo at the 20 -week mark in terms of the NPI-10 score ( $\mathrm{p}=0.048)$ and NPI-4 score $(\mathrm{p}=0.045)$. Cognitive differences between rivastigmine and placebo were noted much earlier at the 12 -week mark. Mild adverse effects related to cholinergic activity were noted much more frequently in the rivastigmine group compared to placebo, although serious adverse events interestingly enough appeared to be more evenly distributed. The open-label study involving rivastigmine [13] showed a $73 \%$ reduction in delusional intensity after 12 weeks in a small sample of 11 patients. Although no patients had to discontinue treatment or experienced severe adverse side effects, the presence of side effects did limit drug titration in some cases. The donepezil study [11] was intended to run for 8 weeks but only 3 patients completed the intended study duration, partly due to adverse effects. The galantamine study [10] showed a significant improvement in delusional intensity as measured by the NPI-4 at the 12-week mark in 25 patients. Improvement in behaviour in general as measured by the NPI-12 was only marginally significant, however. Adverse events were noted to be mild mainly involving the gastrointestinal system but did result in 2 patients discontinuing treatment.

Among the neuroleptics, only 2 studies were done, 1 looking at olanzapine [14] and 1 looking at quetiapine [15]. While both studies used relatively small sample sizes, the olanzapine study used more sound methodology 
Table 1. Drug trials

\begin{tabular}{|c|c|c|c|c|c|}
\hline $\begin{array}{l}\text { Medication and study } \\
\text { design }\end{array}$ & Paper & Participants & Outcome measures & $\mathrm{ADR}$ & Conclusion \\
\hline $\begin{array}{l}\text { Galantamine } \\
\text { 24-week multi-centre } \\
\text { open-label trial with flexible } \\
\text { dose range } \\
(8-24 \mathrm{mg} / \text { day })\end{array}$ & $\begin{array}{l}\text { Edwards } \\
\text { et al. }[10]\end{array}$ & $\begin{array}{l}25 \text { patients with } \\
\text { DLB }\end{array}$ & $\begin{array}{l}\text { Significant improvement on the NPI- } 4 \\
\text { delusional subscale }(\mathrm{p}=0.003)\end{array}$ & $\begin{array}{l}\text { None noted (no } \\
\text { exacerbation of } \\
\text { parkinsonian } \\
\text { symptoms) }\end{array}$ & $\begin{array}{l}\text { Galantamine improves } \\
\text { delusions in patients with } \\
\text { DLB with minimal adverse } \\
\text { effects }\end{array}$ \\
\hline $\begin{array}{l}\text { Donepezil } \\
\text { Open-label 8-week trial } \\
\text { with a flexible dose range } \\
(5-10 \mathrm{mg})\end{array}$ & $\begin{array}{l}\text { Lanctot } \\
\text { et al. [11] }\end{array}$ & $\begin{array}{l}7 \text { patients with } \\
\text { DLB }\end{array}$ & $\begin{array}{l}\text { Delusions, as measured by the NPI } \\
\text { subscale, improved in all } 4 \text { patients } \\
\text { who had delusions at baseline }\end{array}$ & $\begin{array}{l}2 \text { patients } \\
\text { discontinued } \\
\text { treatment due to } \\
\text { side effects }\end{array}$ & $\begin{array}{l}\text { Donepezil has a positive } \\
\text { effect on delusions in } \\
\text { patients with DLB; further } \\
\text { studies are required }\end{array}$ \\
\hline $\begin{array}{l}\text { Rivastigmine } \\
\text { Placebo-controlled, } \\
\text { randomized, double-blind, } \\
\text { multi-centred trial; patients } \\
\text { randomized to placebo } \\
\text { versus rivastigmine (up to } \\
\text { a maximum of } 12 \mathrm{mg} \text { ); } \\
\text { duration: } 20 \text { weeks } \\
\text { followed by a } 3 \text {-week } \\
\text { wash out }\end{array}$ & $\begin{array}{l}\text { McKeith } \\
\text { et al. [12] }\end{array}$ & $\begin{array}{l}120 \text { patients with } \\
\text { DLB }\end{array}$ & $\begin{array}{l}\text { Significant improvement on the } \\
\text { delusions subscale score of the NPI-10 }\end{array}$ & $\begin{array}{l}\text { More patients on } \\
\text { rivastigmine com- } \\
\text { pared to placebo } \\
\text { had adverse events; } \\
\text { no difference in } \\
\text { rates of parkin- } \\
\text { sonism between } \\
\text { the } 2 \text { groups }\end{array}$ & $\begin{array}{l}\text { Rivastigmine is superior to } \\
\text { placebo in the treatment of } \\
\text { delusions among patients } \\
\text { with DLB; minimal adverse } \\
\text { events }\end{array}$ \\
\hline
\end{tabular}

\section{Rivastigmine}

Open-label trial; maximum

tolerated dose (mean: 9.6

$\mathrm{mg}$ daily, range: $3-12 \mathrm{mg}$ )

$\begin{array}{ll}\text { McKeith } & 11 \text { patients with } \\ \text { et al. [13] } & \text { DLB }\end{array}$

et al. [13] DLB
Mean NPI scores fell by $73 \%$ for delusions; 5 of the patients (45\%) experienced very significant clinical improvements that had not been achieved with other treatments, including low-dose neuroleptics
Medication was parkinsonian symptoms tended to improve well tolerated and

Cholinesterase inhibition may be a safe and effective alternative to neuroleptic treatment in DLB; such effects may also prove to be applicable to the management of neuropsychiatric symptoms in PD and AD

Olanzapine

Post-hoc analysis of a subgroup of patients with DLB included in a larger double-blind, placebocontrolled, parallel-group trial of olanzapine for the treatment of psychosis in patients with $\mathrm{AD}$; randomized to placebo, 5, 10 and $15 \mathrm{mg}$

\section{Quetiapine}

Patients with DLB and NPI scores $\geq 3$ on the 3 items (agitation/hallucinations/ delusions) were treated with quetiapine $25-75 \mathrm{mg} /$ day
Cummings 29 patients with et al. [14] DLB
Patients treated with 5- $(\mathrm{p}=0.004)$ and $10-\mathrm{mg}$ doses $(\mathrm{p}=0.008)$ compared to placebo and 15-mg doses had significant reductions in delusion intensity
No exacerbation of Olanzapine is effective in treating delusions at the 5- and 10-mg doses

\section{Takahashi 9 patients with et al. [15] DLB who mani- fested psychotic symptoms and aggressive be- havior

\begin{abstract}
5 patients had a positive response with a decline of $\geq 50 \%$ in the 3 items score on the NPI, 3 patients discontinued participation due to drug side effects, 1 patient showed no significant clinical change in NPI scores; S-A scale scores (measure for parkinsonian symptoms) were not affected by the treatment in any patient

\author{
Somnolence \\ Orthostatic \\ hypotension
}

Quetiapine may be effective in treating some patients with DLB; further doubleblind RCTs are necessary to confirm this observation

ADR = Adverse Drug Reaction; S-A = Simpson-Angus Scale; RCT = randomized controlled trial. 
as it was a post-hoc analysis of an existing randomized controlled trial. In the olanzapine study [14], 29 patients meeting criteria for DLB were extracted from a much larger study involving patients with AD. The study was 6 weeks in duration and involved randomized dosing to 5 , 10 and $15 \mathrm{mg}$. Compared to placebo, patients on olanzapine experienced a significant reduction in delusional intensity at the $5-\mathrm{mg}(\mathrm{p}=0.009)$ and $10-\mathrm{mg}(\mathrm{p}=0.018)$ dose, while change in other behavioural subscales showed no significant difference. No significant adverse effects were noted. The quetiapine study by comparison [15] was open-label in design and used a much smaller sample. Nine patients were recruited, 3 of which withdrew due to adverse side effects including somnolence and orthostatic hypotension. Of the 6 patients who completed the study, 5 had more than a $50 \%$ reduction on the NPI sum score, which combined a measure of delusions, hallucinations and agitation/aggression.

It should also be noted that while all studies showed a positive impact of treatment on delusions, other symptom domains improved as well. All of the studies also demonstrated improvement in visual hallucinations, one of the core clinical symptoms in DLB, in addition to many other behavioural symptoms. Many of the studies also showed positive results on other outcome measures such as cognition, motor symptoms and function.

\section{Discussion}

DLB is a common clinical diagnosis. Although it is quite prevalent, the appropriate treatment of specific behavioural symptoms, such as delusions, is quite complex. There are many reasons for this. First, behavioural symptoms such as delusions tend to be more common in patients with DLB when compared to patients with more traditional forms of dementia such as $\mathrm{AD}[4,5]$. For this reason, patients often need to be treated. Second, the symptoms tend to occur earlier in the course of the disease when other cognitive functions may be well preserved, leading to diagnostic confusion $[4,5]$. Finally, certain forms of treatment, such as neuroleptics, which are often used to treat patients with delusions in other psychiatric conditions such as schizophrenia, have been shown specifically to harm patients with DLB [6, 7]. Cholinesterase inhibitors, it might be argued, are a viable alternative but unfortunately may take time to show effects.

Furthermore, the existing evidence is sparse. Much of this may be due to difficulty in finding adequate numbers of patients. While DLB may be quite prevalent neuro- pathologically, it requires a skilled clinician to diagnose it and to exclude other associated conditions such as PD and AD. This unfortunately results in studies that are either multi-centred or use small samples. Of the studies alluded to in this review, only 1 used an adequate patient sample [12] and only 2 used a randomized controlled design $[12,14]$. Furthermore, psychiatric symptoms in patients with DLB are quite diverse and most studies have focused on correcting behaviour without defining the nature of behavioural symptoms.

Delusions are common symptoms in a number of brain conditions, including traditional psychiatric conditions such as schizophrenia, as well as dementing disorders such as AD and DLB. Why they tend to be more prevalent in patients with DLB is unclear. Various theories have been put forward as to why these symptoms develop in different brain conditions. In illnesses such as schizophrenia, abnormalities involving the dopamine receptor have been postulated [16]. Antipsychotic medications work by decreasing levels of dopamine in the brain, thereby improving psychotic symptoms. Alternatively, the greatest burden of evidence exists for the theory that delusions in patients with dementia of the Alzheimer type arise from selective damage to the frontal lobe. Studies have demonstrated that when compared to patients with dementia of the Alzheimer type who do not have delusions, delusional patients have impaired frontal lobe metabolism, a higher density of senile plaques in the frontal cortex and significantly more deficits in frontal-subcortical circuits [17]. In patients with DLB, the presence of delusions has been linked neuropathologically to the presence of Lewy bodies in the neocortex [18] and increased M1 muscarinic receptor binding in the temporal cortex [19].

Further studies need to be done to clarify the treatment of delusions in patients with DLB. The small number of studies using cholinesterase inhibitors showed effectiveness. However, only 1 medication, rivastigmine, used a relatively large sample size and a randomized double-blinded placebo-controlled design [12]. Adverse effects were noted to be higher than in the placebo group and consisted mainly of gastrointestinal symptoms. Galantamine [10] also showed impressive results with minimal adverse events. The remaining 2 studies $[11,13]$ used very small sample sizes, so it is hard to extrapolate much, although the results appear encouraging. There is some suggestion based on these studies that cholinesterase inhibitors may be effective, although more studies need to be done to clarify their effectiveness. Their relative effectiveness does seem to suggest a role for the cholinergic system in the development of delusions. The evi- 
dence for effectiveness of neuroleptics is more limited. The olanzapine study [14] had a reasonable sample size and was a post-hoc analysis of an existing randomized controlled trial. It showed effectiveness at specific dosages ( 5 and $10 \mathrm{mg}$ ) but noted that effectiveness declined as medication dosage increased to $15 \mathrm{mg}$. Perhaps this suggests a dose-specific effect. Adverse events were minimal even at reasonably high dosages. Quetiapine [15] again showed effectiveness but the number of patients was so small it is hard to say definitively whether the drug was effective. Side effects noted included orthostatic hypotension and somnolence. It should be noted that as in Alzheimer clinical trials the possibility exists of a strong placebo response. Behavioural symptoms may be exquisitely sensitive to this response given that they may respond better to the increased surveillance that comes with a clinical trial. The rivastigmine study, which employed a randomized placebo-controlled design, did show a rather robust placebo response which only started to differ from the drug treatment group at 20 weeks. It is entirely possible therefore that some of the positive responses noted in the open-label studies could be attrib- uted to a placebo type response, particularly in the shorter duration studies such as the donepezil [11] and olanzapine [14] studies. Further large-scale studies are needed using a randomized placebo-controlled design before any definitive conclusions can be drawn.

\section{Conclusion}

In summary, delusions are common clinical symptoms in patients with DLB. Their treatment is complicated by the fact that the very medications used to treat delusions in other brain illnesses may have adverse effects $[3,4]$. Cholinesterase inhibitors take time to work, while traditional antipsychotic medications may have serious adverse effects. Studies to date looking at these symptoms suffer from many limitations including lack of randomized placebo-controlled trials and small sample sizes. The studies seem to suggest a role for cholinesterase inhibitors, while less studies have been done looking at neuroleptics. Clearly further multi-centred, randomized, controlled trials are required before a definitive treatment can be proposed.

\section{References}

1 McKeith IG, Mintzer J, Aarsland D, et al: Dementia with Lewy bodies. Lancet Neurol 2004;3:19-28.

$\checkmark 2$ Litvan I, Bhatia KP, Burns DJ, et al: SIC Task Force Appraisal of clinical diagnostic criteria for parkinsonian disorders. Mov Disord 2003; 18:467-486.

-3 McKeith IG, Dickson DW, Lowe J, et al: Diagnosis and management of dementia with Lewy bodies. Neurology 2005;65:18631872 .

$\checkmark 4$ McKeith IG, Perry RH, Fairbairn AF, Jabeen S, Perry EK: Operational criteria for senile dementia of Lewy body type (SDLT). Psychol Med 1992;22:911-922.

$\checkmark 5$ Birkett DP, Deseousky A, Han L, Kaufman M: Lewy bodies in psychiatric patients. Int J Geriatr Psychiatry 1992;7:235-240.

6 McKeith I, Fairbairn A, Perry R, Thompson P, Perry E: Neuroleptic sensitivity in patients with senile dementia of Lewy body type. BMJ 1992;305:673-678.

7 Swanberg MM, Cummings JL: Benefit-risk considerations in the treatment of dementia with Lewy bodies. Drug Saf 2002;25:511523.

$>$ Aarsland D, Perry R, Larsen JP, McKeith IG, O’Brien JT, Perry EK, Burn D, Ballard CG: Neuroleptic sensitivity in Parkinson's disease and parkinsonian dementias. J Clin Psychiatry 2005;66:633-637. $\checkmark 9$ Ballard C, Piggot M, Johnson M, Cairns N, Perry R, McKeith I, Jaros E, O’Brien J, Holmes C, Perry E: Delusions associated with elevated muscarinic binding in dementia with Lewy bodies. Ann Neurol 2000;48: 868-876.

10 Edwards KR, Hershey L, Wray L, Bednarczyk EM, Lichter D, Farlow M, Johnson S: Efficacy and safety of galantamine in patients with dementia with Lewy bodies: a 12-week interim analysis. Dement Geriatr Cogn Disord 2004; $17: 40-48$.

11 Lanctot K, Herrmann N: Donepezil for behavioural disorders associated with Lewy bodies: a case series. Int J Geriatr Psychiatry 2000;15:338-345.

12 McKeith I, Del Ser T, Spano P, Emre M, Wesnes K, Anand R, Cicin-Sain A, Ferrara R, Spiegel R: Efficacy of rivastigmine in dementia with Lewy bodies: a randomized, doubleblind, placebo-controlled international study. Lancet 2000;356:2031-2036.

13 McKeith I, Grace J, Walker Z, Byrne EJ, Wilkinson D, Stevens T, Perry EK: Rivastigmine in the treatment of dementia with Lewy bodies: preliminary findings from an open trial. Int J Geriatr Psychiatry 2000;15:387392.
14 Cummings JL, Street J, Masterman D, Clark SW: Efficacy of olanzapine in the treatment of psychosis in dementia with Lewy bodies. Dement Geriatr Cogn Disord 2002;13:6773.

15 Takahashi H, Yoshido K, Sugita T, Higuchi $\mathrm{H}$, Shimizu T: Quetiapine treatment of psychotic symptoms and aggressive behaviour in patients with dementia with Lewy bodies: a case series. Prog Neuropsychopharmacol Biol Psychiatry 2003;27:549-553.

-16 Goldsmith SK, Shapiro RM, Joyce JN: Disrupted pattern of D2 dopamine receptors in the temporal lobe in schizophrenia: a postmortem study. Arch Gen Psychiatry 1997;54: 649-658.

17 Paulsen JS, Ready RE, Stout JC, Salmon DP, Thal LJ, Grant I, Jeste DV: Neurobehaviors and psychotic symptoms in Alzheimer's disease. J Int Neuropsychol Soc 2000;6:815820.

-18 Ballard C, Jacoby R, Del Ser T, et al: Neuropathological substrates of psychiatric symptoms in prospectively studied patients with autopsy-confirmed dementia with Lewy bodies. Am J Psychiatry 2004;161:843-849.

19 Teaktong T, Piggott MA, McKeith IG, Perry RH, Ballard CG, Perry EK: Muscarnic M2 and M4 receptors in anterior cingulate cortex: relation to neuropsychiatric symptoms in dementia with Lewy bodies. Behav Brain Res 2005;161:299-305. 